\title{
Self-Concepts, Domain Values, and \\ Self-Esteem: Relations and Changes at \\ Early Adolescence
}

\section{Jacquelynne S. Eccles, Allan Wigfield, Constance A. Flanagan, Christy Miller, David A. Reuman, and}

\section{Doris Yee}

\section{University of Michigan}

ABSTRACT We assessed how children's self-concepts of ability for mathematics, Englısh, social, and physical skills activities, ratıngs of the importance of these activities, and general self-esteem change across the transition to junior high school Three types of change were assessed change in mean levels, change in stability, and change in relationships. Twice each year during the sixth and seventh grades, 1,450 children completed questionnaires Mean levels of children's self-esteem were lowest immediately after the transition, but recovered during seventh grade Self-concept of ability and importance ratings for math and sports activities showed linear declines Self-concept of ability for social activities showed a cubic trend, but importance ratıngs for social actıvities declined in a linear fashion Children's self-concepts of ability for math and English became less stable across the junır high transition, whereas beliefs about other activities and general self-esteem were more stable in seventh grade

The development of personality and the links between personological characteristics and behavior have long interested psychologists Recently, atten-

This research was made possible by grants from the National Institute of Mental Health (MH 31724 to Jacquelynne $S$ Eccles), the National Institute of Child Health and Human Development (HD 17296 to Jacquelynne S Eccles), and the National Science Foundation (BNS 85-10504 to Jacquelynne S Eccles and Allan Wigfield) Address correspondence and requests to Jacquelynne S Eccles, 5207 Institute for Social Research, University of Michigan, Ann Arbor, MI 48106 We would like to thank our colleagues, Carol Midgley, Harnet Feldlaufer, Jan Jacobs, Dave Klingel, and Doug MacIver, at the Achievement Research Laboratory, for all their help in collecting and processing the data

Journal of Personalin 57 2, June 1989 Copynght (C) 1989 by Duke University Press CCC 0022-3506/89/\$1 50 
tion has focused on self-concept as a critical component of personality Many theonsts have attempted to articulate exactly what the self-concept is and how it relates to behavior There is reasonable consensus that it is best to think about the self-concept as having many components and subcomponents that include appraisals of one's competencies and charactenstics, evaluations regarding the relative importance or value of these vanous competencies and charactenstics, and a general sense of one's self-worth or selfesteem (Epstein, 1973, Harter, 1983, James, 1890/1963, Kihlstrom \& Cantor, 1984, Markus \& Nurius, 1986, Rosenberg, 1979, Shavelson \& Bolus, 1982, Shavelson, Hubner, \& Stanton, 1976) Developmental psychologists have been quite interested in how these vanous aspects of self-concept and self-esteem change with age (e g , Dusek \& Flaherty, 1981, Eccles, Midgley, \& Adler, 1984, Harter, 1982, 1983 1985a, 1985b) Several developmental psychologists have suggested that early adolescence may be an especially interestıng tıme to look at these changes (Eccles, Midgley, \& Adler, 1984, Enkson, 1968, Higgins \& Parsons, 1983, Rosenberg, 1979, Simmons, Rosenberg, \& Rosenberg, 1973) In this article we investigate developmental changes in both the level and the stability of the following components of early adolescents' self-concept ( $a$ ) appraisals of their ability in four specific areas (henceforth referred to as self-concept of ability), (b) the importance they attach to competence in each of these four areas, and (c) general self-esteem

In keeping with current approaches to developmental change (Damon \& Hart, 1986, Lerner, 1986), we investigated three types of change change in mean levels across tıme, change in the within-subject stability across time, and changes in the association of the variables of interest to a related construct Change in mean level tells us something about how the population as a whole changes over time, usually in response to some systematic changes in the environment Stability coefficients tell us something about the stability of individual differences within the population over time Changes in the association of the variable of interest with a related construct tell us something about changes in the qualitative meaning of either or both variables to individual subjects

Early adolescence is a particularly interesting time to study all three types of personality change First, for reasons discussed more fully later, early adolescence is a time when the perceived importance of various domains may be changing Second, it is a time when identity formation is presumed to be a very active process In some regards, identity forma- 
tion can be seen as the process by which individuals (a) develop a more realistic picture of their relative competencies, $(b)$ come to know what they value about themselves, and then $(c)$ ground their self-esteem around these values Viewed this way, identity formation is directly related to the three components of self-concept we are studying Third, several researchers have suggested that early adolescence is a time of gender-role intensification, a tıme when males and females will be pressured to adopt more extreme differences in their interests, domain values, and activities (Eccles, 1987a, Hill \& Lynch, 1983, Parsons \& Bryan, 1978) Fourth, it is a time when most children in the United States experience a major school transition that involves substantial changes in the nature of their social environment

\section{Developmental Changes in Self-Concepts of Abulity and Self-Esteem at Early Adolescence}

Theorists such as Erık Erikson (1968) have proposed that early adolescence is a time of "storm and stress," and that great change occurs in children's self-perceptions and identity at that tıme In support of this view, Simmons et al (1973), in a cross-sectional study of approximately 1,000 students aged 8 to 17 , found that the early adolescence period (ages 11 to 14) was the time in which children's self-perceptions were the most negatıve Compared to younger and older children, the 11- to 14-year-old children were more self-conscious and had lower overall self-esteem, less confidence in their academic abilities, and less stable self-perceptions Simmons et al tied these disturbances to the change in the school environment that occurs for many children during early adolescence The most dramatic differences they observed were in the group that had just made the transition to junior high school

Attempts to replicate these findings have yielded quite mixed results (see Eccles, Midgley, \& Adler, 1984, Eccles \& Midgley, in press, for reviews) For example, Thomberg and Jones (1982) reported a general cross-sectional decline in self-esteem during Grades 4 to 9 Similarly, but usıng a longitudınal desıgn, Sımmons and Blyth (1987) found a decline in general self-esteem during early adolescence but only for girls And our research group has found a decline in self-concept of math ability but not English ability over Grades 5 to 12 (Eccles, Midgley, \& Adler, 1984) Others, however, have found little evidence of any decline dunng the early adolescent period in either specific ability self-concepts or gen- 
eral self-esteem Dusek and Flaherty (1981), in a large-scale 3-year longitudinal study of children in Grades 5 through 12, found more stability than change in children's self-concepts (measured by children's perceptions of their adjustment, achievement/leadership, sociability, and masculınity/femınınity) Nottelman (1987) found that students' self-esteem scores increased slightly following the transition to junior high school O'Malley and Bachman (1983), using the same self-esteem measure that Simmons et al (1973) used, also reported small increases in children's self-esteem through the adolescent years

What are we to make of these inconsistencies? First, the studies vary greatly in the specific measures used to assess self-concepts of ability and self-esteem, making exact comparisons difficult In addition, as noted above, those studies that have looked at self-concepts in different subject areas have found different patterns of change associated with the different subject areas (e g Eccles, Midgley, \& Adler, 1984) We have also argued (Eccles \& Midgley, in press, Eccles, Midgley, \& Adler, 1984) that specific classroom characteristics will affect these self-concepts and, consequently, that changes in these specific classroom characteristics will affect the nature of longitudinal changes in self-concepts Studies are needed which use similar measures across time and which focus on domain-specific self-concept measures as well as global measures of self-concept and self-esteem

Second, although not all studies actually specify when the measures were collected, the studies reporting this information vary as to the time of year in which the measures were collected Presumably, the other studies also vary on this dimension There is good reason to suspect that time of year will impact on self-concepts of ability and self-esteem measures, especially during those school years when the students may have just undergone a school transition as well as a grade-level change For some variables, these transitional effects should be most marked in the fall immediately after the transition into the new environment But even within the fall term some of these effects may change For example, there may be an initial honeymoon effect with the transition to junior high school, followed by a decline as the children adjust to the more harsh realities of the junior high school environment For other variables, changes resultung from a different environment or different teacher may take longer to emerge and so may be more marked in the sprning of the school year

Third, and most important, to the extent that we think that developmental changes in self-concept reflect systematic changes in the social 
environments of the children rather than global properties of the adolescent period (Higgins \& Parsons, 1983), we would expect variations in these changes depending on the types of environmental changes the children experienced We can assume that most of the children in the studies reviewed above were experiencing some type of change in their school environment durnng these years At the very least, most will have moved from a small elementary school to a larger, more impersonal junior high or middle school Traditional junior high schools differ from traditional elementary schools in numerous ways For example, they are larger, more impersonal, and more departmentalized In addition, according to Eccles and Midgley (in press), they are characterized by more formal, controlling, and less trusting relationships between students and teachers, a greater emphasis on evaluation and social comparison among students, stricter grading standards, and a disruption of children's social networks Differences on these dimensions across studies could account for the inconsistencies in the data

Unfortunately, in some of the studies cited earlier, almost no information is provided about etther the nature or timing of such school-related changes for their subjects We don't know, for example, the year at which the subjects moved from elementary school to the next level of schooling (1 e , junior high school or middle school) We also know little about the types of social environments in either school setting In addition, classrooms and teachers within a grade level or school building vary on the charactenstics outlined above To the extent that these classroom level vanations are systematically associated with subject matter area, we would expect to see change in adolescents' self-concepts for some subject areas and not others Virtually no studies have gathered information which would allow for analysis at the subject matter level

\section{Developmental Changes in Domain Values}

We know very little about the developmental changes in the importance and value children place on competence in various domains Although once again the data are not entrrely consistent, studies focusing on children's attutudes toward school and school subjects suggest a general developmental decline across the grades from third to tenth in the value children place on academic achievement and on their intrinsic interest in and motivation for schoolwork (Eccles, Midgley, \& Adler, 1984, Eccles \& Midgley, in press, Harter, 1981) Not surprisingly, the nature of the 
instructional environment has a significant effect on the magnitude and direction of these changes (Feldlaufer, Midgley, \& Eccles, in press, Moore, 1983, Power, 1981)

Relatively little work has been done on developmental changes in the value children place on other activity domains The importance attached to peer acceptance has received the most attention There is some indication that the importance of social competence may increase over this period, especially for girls (Berndt, 1987, Crockett, Losoff, \& Petersen, 1984, Walker \& Greene, 1986) Even less work has been done on the relative importance attached to competence across various domains despite the fact that the relatıve importance one attaches to competence in these domains may influence how strongly one's self-concept of ability in each domain is related to one's general self-esteem (Harter, 1985a, 1985b, James, 1890/1963) But studies focusing on specific subject areas and on the link between competence in different domains and one's self-esteem suggest that academic competence should remain quite important over this penod, especially for boys (Stein \& Smithells, 1969, Walker \& Greene, 1986)

In the present study we extend previous work by examining change across the junior high school transition in children's general self-esteem, as well as changes in their self-concepts of ability in and valuing of mathematics, English, sports, and social activities These variables were chosen because they represent central constructs in achievement motivation theory Self-esteem, perceptions of ability, and the value attached to different tasks have all been positioned to influence students' achievement behavior (Eccles et al , 1983) The different activity areas (academic, social, and physical) were chosen because they represent activity domains that are common to childhood By examıning general self-esteem, self-concepts of ability in specific areas, and the importance children attach to competence in these areas, we can provide a more complete picture of how children's self-schema change at this time, and so clarify some of the conflicting findings in previous work

We believe that change in self-esteem and changes in self-perceptions about, and perceived importance of competence in, specific activities will follow different patterns, reflecting differential sensitıvity to specific environmental changes General self-esteem and specific self-concept of one's social ability should be most disrupted immediately following the transition to junior high as children adjust to the new school environment and develop new social networks and roles (Berndt, 1987) As children adjust to the transition, both self-esteem and self-concept of social abil- 
ity should increase Children's self-concepts of ability in, and valuing of, different academic activities should show a less marked transition effect, and a more marked within-year effect In addition, the patterns of change for academic subjects should vary across different subject areas There are systematic differences between our subjects' sixth- and seventh-grade math classrooms In comparison to the sixth-grade math teachers, the seventh-grade math teachers provide the students with less autonomy and less opportunity to participate in decision making They trust their students less, feel less effective as teachers, are more likely to use whole class instruction, are less likely to use cooperative learning programs, and give students lower grades (Feldlaufer, Midgley, \& Eccles, 1988, Midgley \& Feldlaufer, 1987, Midgley, Feldlaufer, \& Eccles, in press) These are the types of classroom level changes that Eccles, Midgley, and Adler (1984) hypothesized would lead to a decline in specific ability self-concepts and in the perceived importance of competence in a particular subject area Consequently, we predict that both self-concepts of math ability and the perceived importance of math competence will decline during seventh grade after remaining stable durıng sixth grade Since we have not gathered comparable classroom climate data for English instruction, we cannot make specific predictions for the direction of change for the English vanables But other studies suggest that seventh-grade math classrooms are more likely than English classrooms to be characterized by the negative features outlined above (Eccles, Midgley, \& Adler, 1984) If this is true, then we would expect no withinyear decline in the students' English self-concepts and perceived importance, and might even see an increase in these self-concept beliefs due to the relatively more positive classroom atmosphere in English than in math Finally, given the sparsity of data on sports, we will not make a prediction about the nature of developmental change for the sports domain

Our work builds on the previous work in another way We look at the stability of individual differences for all three sets of measures (self-esteem, self-concepts of ability, and perceived importance of competence) We expect the short-term stability coefficients for the academic subjects and for the social domain to be lower for the 6-month period over the school transition than for the 6-month period within each of the two school years, since during the former time period students expenence a major disruption in their academic and social environments This disruption should create a shift in the reference groups the children use to eval- 
uate their competency in each of these three domains If this is true, then one would expect reduced stability over this penod In contrast, since sports is a domain in which most children participate outside of school, we do not expect the school transition to disrupt the stability coefficients for the two sports indices Finally, given that adolescence is a period of identity consolidation, we expect higher within-school year stability coefficients for the seventh grade than for the sixth grade for each of the activity domains

We also compare the stability coefficients of the self-concept measures Eccles, Adler, and Meece (1984) suggested that math self-concepts ought to be more stable than English self-concepts because children are more likely to attribute their successes and fallures to ability in math than in English In addition, performance feedback in math is more concrete and more clearly linked to specific performance criteria than performance feedback in English A similar rationale leads us to predict that sports self-concepts should be more stable than social self-concepts

In addition, work by investigators such as Kagan and Moss (1962) suggests that gender-role related personality characteristics and behav1ors may be more stable in the sex for which the behaviors are genderrole appropriate (e $\mathrm{g}$, aggressive behaviors will be more stable in boys than in girls) To the extent that this is true, girls should evidence higher stability than boys when asked about their self-concepts in female-typed domains, and boys should evidence higher stability than girls when asked about their self-concepts in male-typed domains

Finally, our work builds on previous developmental work by lookıng at changes in the associations of ability self-concepts to more objective competence ratıngs In particular, we look at the "accuracy" of children's self-concepts We define "accuracy" as the relation between children's specific ability self-concept and their teachers' ratıng of that specıfic ability Using a similar definition of "accuracy," Harter (1982) found a sharp cross-sectional decline in the accuracy of children's academic self-concepts following the transition to junior high school at the seventh grade, she attributed this decline to the junior high school transition We assess this hypothesis more directly by comparing the "accuracy" of our subjects' math self-concepts at four tıme points surrounding this transition 


\section{METHOD}

\section{Study Overview}

The data presented in this article were collected as part of a larger invest1gation (the Transitions in Early Adolescence Project) that is assessing the impact of change in the classroom and family environments on early adolescents' beliefs, values, motives, and behaviors in several activity domains The study has a 2-year, four-wave design Students completed questionnaires twice each year (fall, spring) over the 2 years of the study Hence, it was possible to assess both withın- and across-year changes in students' self-perceptions

\section{Sample}

Twelve school districts located in low- to middle-income communities were recruited for this project The districts were located within 50 miles of a large midwestern city Almost $90 \%$ of the students in the districts are Caucasian All elementary schoolteachers in those districts who taught mathematics to s1xth-grade elementary school students were recruited Year 1, $95 \%$ of the teachers, representing 143 classrooms, agreed to participate Students were followed Year 2 into 171 seventh-grade junır high school mathematics classrooms In Year 2 all eligible junior high school teachers agreed to participate of the eligible sixth-grade students, $79 \%$ agreed to participate A student attrition rate of $11 \%$ between Years 1 and 2 occurred primarily because of students moving away from participatıng districts

A subset of the student sample from the Transitions project is used in the analyses reported here The sample consists of those students who made a transition from a sixth-grade elementary school to a seventh-grade junior high school, who completed questionnaires at all four waves of the study, and who could be grouped according to their relative valuing of academics ( $1 \mathrm{e}$, schoolwork in general and mathematıcs), social actıvities, and sports activities This sample includes approximately 1,450 students (The exact figure vanes slightly from analysis to analysis due to variations in each subject's specific missing data )

\section{Student Questionnaire}

Student questionnarres measuring a large number of theoretical constructs across multiple-activity domains were admınıstered by field staff to students durıng the period they normally received mathematics instruction The questionnaires were administered for 2 consecutive days in the fall and spring of each school year The questionnaire contains items assessing a 
broad range of students' beliefs, values, and attitudes concerning mathematics, Englısh, physical skills, and social activities, as well as many other constructs (see Eccles, 1988, for a detalled description) Many of these items have been used in previous studies by Eccles and her colleagues (e $\mathrm{g}$, Eccles et al , 1983, Kaczala, 1983), and so their psychometric properties are well known These psychometric properties are reported in Parsons (1980) and Eccles (1988)

The dependent variables included in the present article are (a) students' self-esteem, assessed by Harter's (1982) Self-Esteem Scale, (b) children's self-concepts of ability ratıngs in mathematics, Englısh, physical skılls, and social skills, assessed by two items in each domain, and (c) the importance children attach to competence in each of the four domains, assessed by one item in each domain Each of the items used to assess self-concept of ability and perceived importance was assessed using a 7-point Likert scale anchored at the extremes All reliabilities for the self-concept scales exceeded 70 All vanables were measured at each of the study's four waves

\section{Students' Relative Valuing of Activittes}

At Wave 1, students' beliefs about the relative importance of being good at schoolwork in general, mathematics, social activities, and sports were assessed Students answered four items each pairing two of these activities (e g , makıng friends-schoolwork, sports-math, schoolwork-sports, math-making friends), and indicated which of the two activities was more important for them to be good at Students' ratıngs were used to form the four possible unique groups of children with clearly differing domain value patterns for academic, sports, and social activities Eccles (1987b) argued that one major characteristic that ought to directly affect behavioral choices, especially in the achievement domain, is the relative valuing of various activities and domains

Group 1 Feminine values identified group Group 1 is comprised of students who value being good at making friends more than being good at both schoolwork and mathematics, and who value both schoolwork and mathematics more than being good at sports activities One hundred ninety-five children are in this group (118 girls, 77 boys) Since this group evidences the traditional female gender-role value system, it is not surprising that it contains more females than males

Group 2 Masculine values identified group Group 2 is compnsed of students who value being good at sports more than being good at both schoolwork and math and who value being good at both schoolwork and mathematics more than being good at making friends At total of 87 children are 
in this group ( 18 girls, 69 boys) Since this group evidences the traditional masculine gender-role value system, it is not surprising that it contains more males than females

Group 3 Nonacademically identified group This group is comprised of students who value being good at sports and making friends more than being good at both schoolwork and mathematics A total of 244 children are in this group ( 79 girls, 165 boys)

Group 4 Academically identified group This group is comprised of students who value being good at both schoolwork and mathematics more than being good at either makıng friends or sports activities A total of 924 children are in this group ( 558 girls, 366 boys) The size of this group probably reflects the joint influences of the importance of school to these children, the fact that the questionnaire was administered in a school setting, and social desirability

\section{Teacher Ratings of Students' Math Abilnty}

Children's mathematics ability was assessed using sixth- and seventh-grade teachers' ratıngs of each child's natural talent in mathematics and performance in math relative to other students on 7-point Likert scales anchored at the extremes Scores on these two items were combined to form a composite ratıng The sixth-grade teachers' composite ratıngs were correlated with children's math self-concept of ability ratings at Waves 1 and 2, the seventhgrade teachers' composite ratings were correlated with the children's math ability self-concept at Waves 3 and 4

\section{Scoring}

Each item on the self-esteem scale was answered on the 4-point scale developed by Harter (1982), and the scores were coded so that higher scores indicated higher self-esteem The scores for each item were summed to form a total score for self-esteem, which could range from 5 to 20 All other constructs were assessed using 7-point scales, with higher scores indicating higher self-concepts of ability and importance, respectively For the selfconcept of ability construct, the two items measuring self-concept of ability in each domain were averaged, so that scores on self-concept of ability, likIng, and importance range from 1 to 7 Percelved importance of competence was measured with one item in each domain 


\section{RESULTS AND DISCUSSION}

\section{Mean Differences in Chuldren's Beliefs \\ Across Time}

\section{Overview of analyses}

Each set of dependent variables (self-esteem, self-concept of ability for the four activities, and ratings of the importance of the four activities) was analyzed in separate repeated measures multivariate analyses of varrance (MANOVAs) Because of the large sample size and large number of possible effects, the 01 level of significance was adopted for the overall tests All MANOVAs except the MANOVA on the self-esteem scores included two between-subject factors (students' relative valuing of different activities and gender), and two withın-subjects factors (activity domain and time of measurement) The MANOVA on self-esteem scores had only one within-subject factor, time of measurement For the time of measurement factor, significant effects were interpreted by examining whether change over time was linear, quadratic, or cubic Quadratic trends indicate one shift in direction over time, and cubic trends indicate two shifts over time (Kırk, 1968) These trends can be used to assess how the junior high transition influences children's beliefs Significant activity domain main effects or interactions with other factors were followed up with three-way MANOVAs that assessed gender, relative valung, and tume of measurement effects separately in each activity domain These analyses provided univariate follow-up tests for the vanous significant multivar1ate findings, and in these univanate tests, we present findings significant at the 05 level Simple effects tests were used to compare specific means if the univanate analyses were significant We present findings as different if these tests were significant at the $p<05$ level

Self-esteem Overall change in children's self-esteem scores is presented in Figure 1 for both boys and girls As predicted, the time of measurement effect is significant, $F(3,1059)=433, p<01$ As can be seen in Figure 1 , self-esteem scores following the transition to junior high school declined as predicted However, as the significant cubic trend indicates, there are significant withın-year changes as well, $F(1,1061)=1283, p<001$ In both sixth and seventh grade, children's self-esteem scores are higher in the spring than in the fall $(p<05)$ Children's self-esteem scores are lowest in the fall of their seventh-grade year

Self-concept of ability Overall change in self-concept of ability in each domain is shown in Figure 2 As the significant two-way interaction of time 


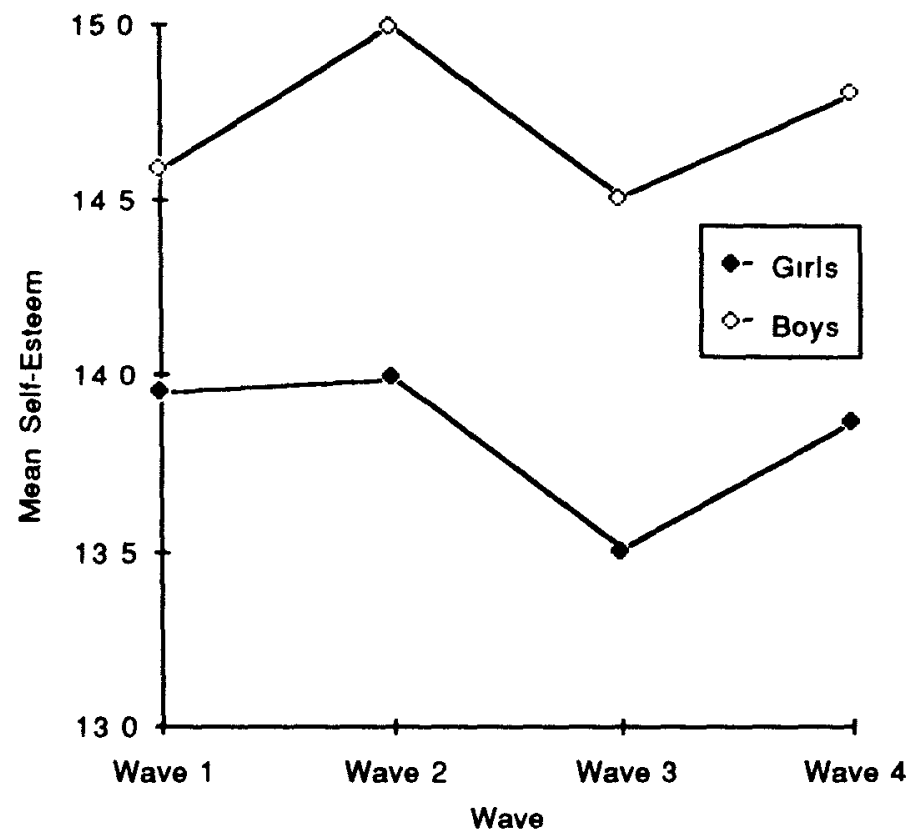

\section{Figure 1}

Mean Self-Esteem Scores for Boys and Gurls at All Four Warves

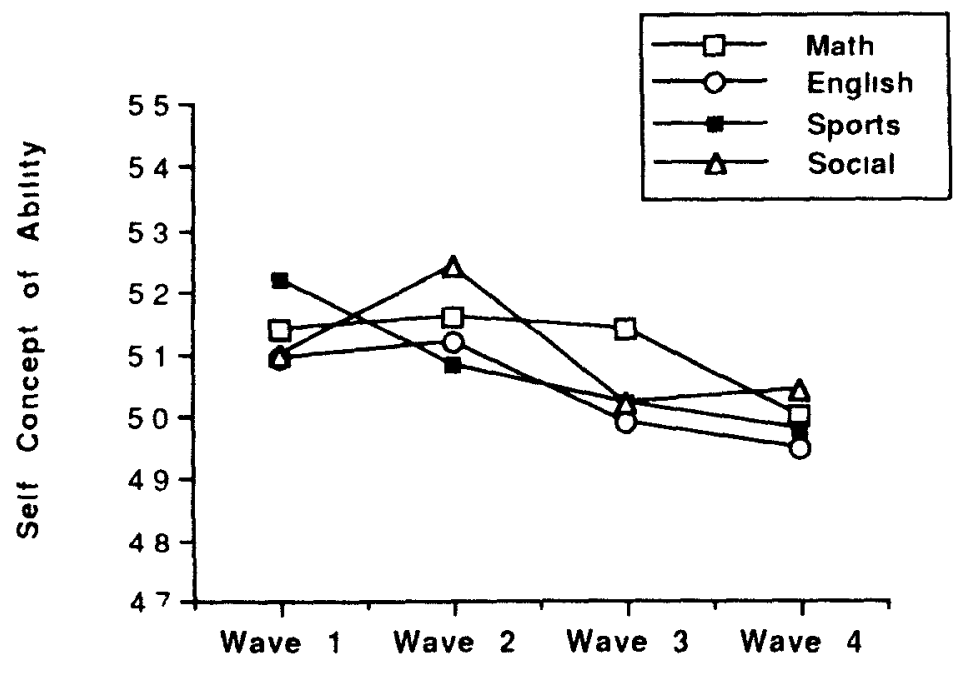

Figure 2

Mean Self-Concept of Ablity Scores in Each Domain at All Four Waves 
of measurement by activity domain indicates, the pattern of change differs across the domains, $F(9,1119)=325, p<001$ The univanate follow-up tests show that for math both the linear and quadratic trends are significant, $F(1,1127)=990, p<01$, and $F(1,1127)=551, p<05$, respectively Simple effects tests suggest that the decline in math ability self-concept is primarly due to the decline which occurs between Waves 3 and 4 Children's mathematıcs ability self-concepts are similar at Waves 1, 2, and 3 In contrast the mean for Wave 4 is significantly lower than the mean at each of the other three waves Thus, as predicted, for mathematics the primary decline comes after the transition to the seventh grade, when the majonty of the children were exposed to the more negative instructional climate in mathematics described in the introduction (Feldlaufer, Midgley, \& Eccles, 1988) Also as predicted, it takes time for the classroom experience to influence children's self-concept of math ability For English, as the significant linear trend indicates, $F(1,1127)=406, p<05$, beliefs declined steadily from Wave 1 through Wave 4

There is also a strongly signficant decreasing linear trend in children's self-concepts of ability in sports, $F(1,1127)=1742, p<001$, and a weaker quadratic trend, $F(1,1127)=406, p<05$ These effects reflect the gradual decline over time in the children's ratıngs of their self-concepts of sports ability The largest change occurs between the fall and spring of sixth grade $(p<05)$

Finally, children's self-concepts of ability for social activities increase during sixth grade and then, as predicted, decrease following the transition to junior high school, as the significant cubic trend indicates, $F(1,1127)=$ $914, p<01$ Contrary to our prediction, and contrary to the self-esteem results, the children's self-concept of social ability does not significantly rebound over the course of the seventh-grade year

Percelved importance Overall change in children's ratings of the importance of being good at different activities is shown in Figure 3 As predicted, the two-way interaction of activity domain by time of measurement is significant, $F(9,1172)=821, p<001$ The univanate follow-up tests show that significant changes over time occur for the importance ratıngs of mathematics, English, and social activities The importance children attach to mathematics decreases across the four waves, as the significant linear trend shows, $F(1,1180)=4482, p<001$ As predicted, the biggest decrease comes between the fall and spring of seventh grade, which is reflected in the significant cubic trend, $F(1,1180)=1034, p<01$

Children's ratings of the importance of English show a significant cubic trend, $F(1,1180)=1846, p<001$ This effect reflects two trends an increase in perceived importance of English within each school year, and a substantial drop in perceived importance across the transition it is not clear 


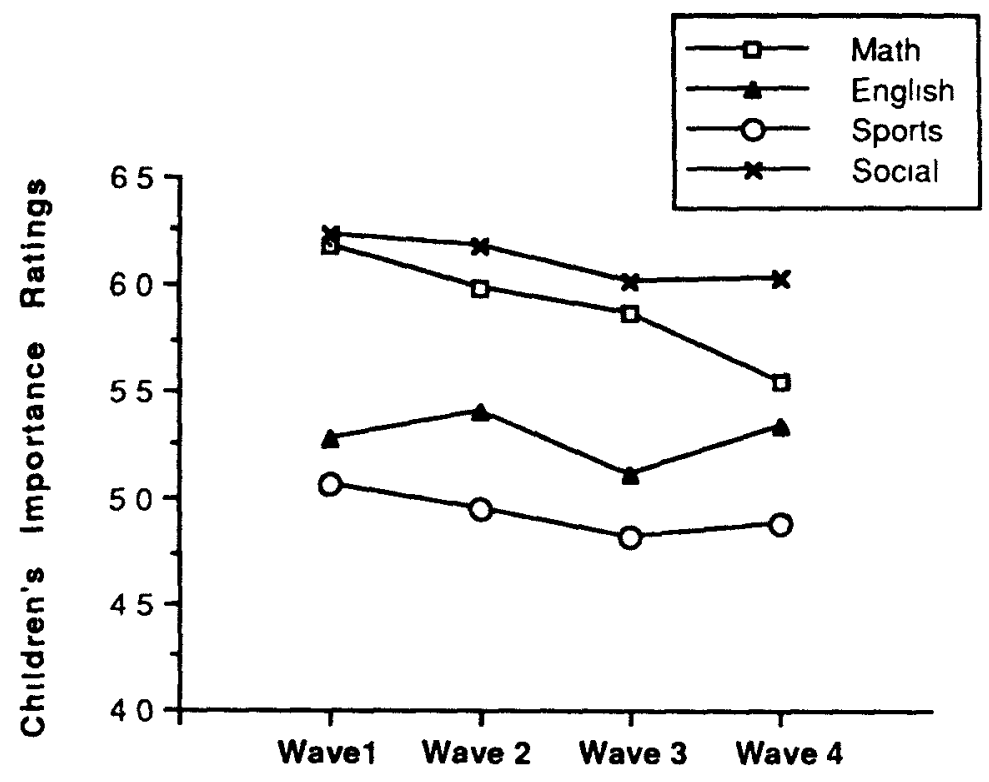

Figure 3

Mean Importance Ratıngs in Each Domain at All Four Waves

why English shows this transitional effect, especially given its recovery over the year and the lack of a wave effect on the self-concept of English ability But the divergent pattern of change in the importance the children attached to English versus math competence supports our hypothesis that the decline in the children's perceptions of the importance of math competence results from some unique aspect of the children's experiences with math instruction and not from a more general psychological or expenential phenomenon

Contrary to prediction, the importance children attach to social skills decreases slightly and steadily across this time span as the significant linear trend indicates, $F(1,1180)=976, p<001$ Although the quadratic trend is not significant, the children's rating of the importance of social competence is significantly lower in the seventh grade than in the sixth grade $(p<$ 05) And, like the self-concept of social ability ratings, it does not rebound during seventh grade, as one might expect it to if the decline reflected the initial disruption of the children's social networks as they moved into junior high school Perhaps these early adolescent children have lowered the value they attach to social competence to compensate for their lowered sense of social competence in this new environment Finally, as shown by the significant linear trend, $F(1,1180)=453, p<01$, the importance students attach to physical skills decreases across waves 
In general, across all waves, these children rate social skılls as most important to them, followed closely by competence in mathematics and then by competence in English $(p<05)$ And even though the importance of social skill declines over the four waves, its relative importance compared to math, the second most important domain, is greatest at Wave 4 Competence in sports is rated as least important It is interesting to note that, although the students rated mathematics as substantially more important than Englısh at Wave $1(p<05)$, they end the seventh grade ratıng mathematics as only slightly more important than English This pattern is consistent with the developmental trends reported by Eccles, Midgley, and Adler (1984) and Brush (1980), in which students get progressively more negative towards mathematics across the junior and senior high school years but maintain a farly stable view of English Both Eccles, Midgley, and Adler (1984) and Brush (1980) attributed this difference to the changes in mathematics instruction It is also possible that the changes reflect an increasing difficulty in the mathematics being taught This hypothesis seems an unlıkely explanation for the pattern reported here for two reasons First, although some mathematics courses may get more difficult over the course of high school, the average ability level of the students taking these courses is increasing, and these two changes ought to offset each other Clearly, they don't Second, seventh-grade mathematics is not more difficult than sixth-grade mathematics In fact, it is typically a review of elementary school anthmetic

In summary, then, changes in the mean levels of self-esteem, self-concept of ability, and perceived importance provide farrly good support for our hypothesis regarding the impact of the junior high school transition on the average levels of these vanables As predicted, both self-esteem and self-concept of social ability decrease between the end of the sixth grade and the beginning of the seventh grade, also, as predicted, mean levels of self-esteem rebound as the children adjust to the junır high school environment Similarly, the pattern of changes associated with academic subjects supports our prediction that changes in the math classroom environment will have a generally negative impact on the children's beliefs about and self-perceptions in mathematics Both self-concept of math ability and the perceived importance of math declined during the seventh grade In contrast, self-concept of English ability did not decline and the perceived importance of Englısh increased durıng the same tıme period Contrary to our prediction, the importance of social skills did not increase during this developmental perod, instead it decreased But despite the decrease, the importance of social skills remained the most important skill to these children throughout this penod of early adolescent development ${ }^{1}$

1 Because of space limitations, the data on sex, value group, and domain differences cannot be reported here in full Briefly, (a) boys' self-esteem scores were 


\section{Stability of Individual Differences Across Time}

Correlations were computed between measures of the same construct at adjacent and nonadjacent waves in order to determine how stable individual differences on each construct were over time These correlations are presented in Table 1 We discuss the central issue regarding these correlations-how the within-domain stability coefficients change over time, focusing especially on the question of whether there is any evidence of a disruption in the correlations at the transition to junior high school, particularly for general self-esteem, academic self-concept of ability, and social self-concept of ability To assess this issue, we performed significance tests on each relevant pair of correlations (McNemar, 1969) Because of the large sample size, in the overall sample we will report differences at the 01 level or higher For the boys and girls, we will report differences at the 05 level or higher

Changes in stability across ttme Effects of the junior high transition and increasing age on self-esteem and self-concept of ability

We examined the impact of both the transition to junior high school and of increasing age on the stability of children's beliefs by comparing the correlations between variables within sixth grade (Waves 1 and 2) with those across the transition to junior high (Waves 2 and 3 ), and those within seventh grade (Waves 3 and 4) We discuss each construct in turn

Self-esteem In general, self-esteem was not disrupted following the transition to junior high and instead showed a tendency to become more stable as the children got older, especially for the girls For the overall sample, the only significant difference at the 01 level was between the Waves 1 to 2 correlation and Waves 3 to 4 correlation The Waves 3 to 4 correlation was higher

higher than those for girls, (b) boys had higher self-concepts in math and sports, but lower self-concepts in Englısh than girls, and (c) boys rated sports as more important and English and social skills as less important than did girls Throughout the four measurement waves, the ratıngs of self-concept in each of the domain areas, as well as the importance of these domains, closely paralleled the original rankings upon which the four value groups were constructed No significant interactions of sex, value group, or Sex $\times$ Value Group with measurement wave were obtained for any of the dependent vanables, indicating that gender and value group effects were relatıvely constant during the 2-year time period of the study A more complete report of these data is avallable from the first author 


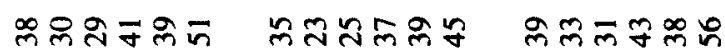

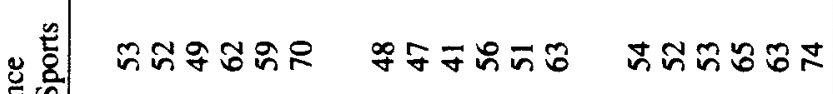

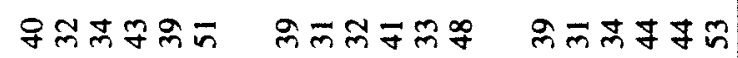

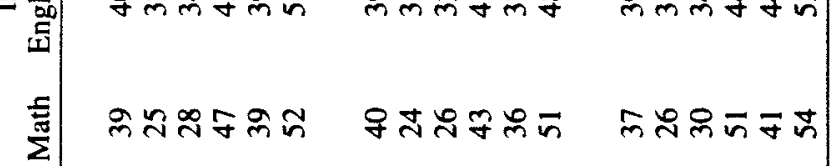
(n)

辛

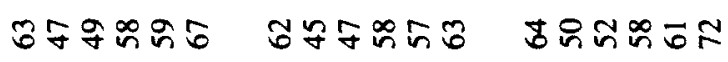

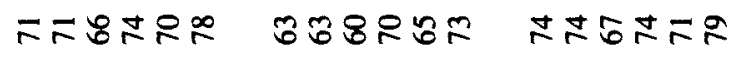

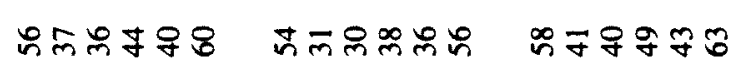

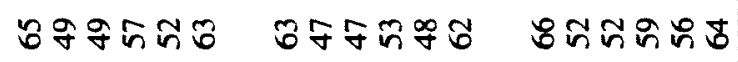

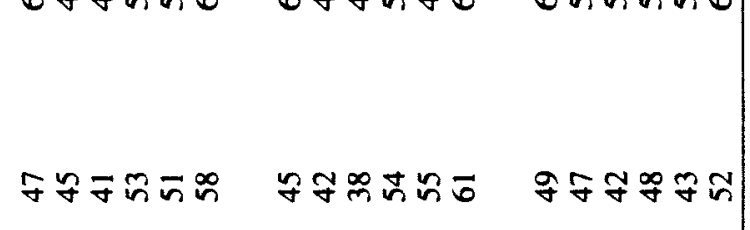

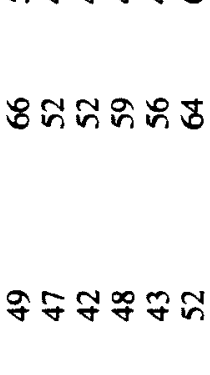

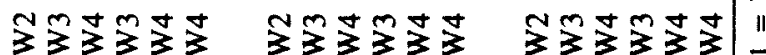

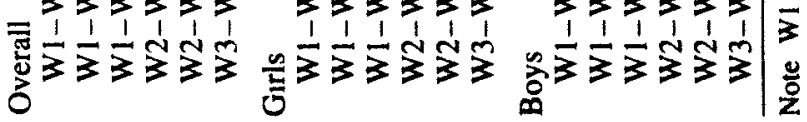


For girls, the same difference was significant in the same direction In addition, the correlation of girls' self-esteem at Waves 2 and 3 was significantly higher than its correlation at Waves 1 and 2 For boys, none of these differences were significant

Self-concept of abılity Math and English As predicted, children's selfconcepts of ability for the academic activities were disrupted following the transition to junior high In the overall sample, for both math and English the Waves 2 to 3 correlations for self-concept of ability were significantly lower than the comparable correlations for Waves 1 to 2 and Waves 3 to 4 In contrast, the Waves 1 to 2 correlations did not differ from the Waves 3 to 4 correlations for the children's self-concept of ability in either math or English

The same pattern of significant differences for both math and English was obtained for girls For boys, only the correlations for self-concept of English ability yielded the same pattern of significant differences The three pairs of correlations did not differ for the boys' math ratings, though the trend was in the same direction as for the overall sample and for girls These results support our prediction that children's perceptions of their academic abilities would be disrupted across the junior high transition

Self-concept of abılity Sports As predicted and contrary to the findings for academic subjects, there was no evidence of disruption in children's selfconcept of sports ability across the junior high transition Instead, the stability coefficients tended to become larger as the children got older For the overall sample, the only significant difference was between the Waves 3 and 4 correlation and the Waves 1 and 2 correlation, with the former being higher For girls, the Waves 1 to 2 correlation was significantly lower than the Waves 2 to 3 and 3 to 4 correlations, the latter two did not differ None of the three companisons were significantly different for boys' self-concept of sports ability, though there was a trend for the correlation of Waves 3 to 4 to be higher than the other two across-wave correlations

Self-concept of ability Social For both the whole sample and for boys in particular, the only significant difference was between the Waves 3 and 4 correlation and Waves 2 and 3 , with the former being higher No significant differences were observed for girls These results provide only moderate support for the hypothesis that self-concept of social ability would be disrupted following the transition to junior high The results are probably better interpreted as reflecting increasing stability of individual differences in social self-concept as children get older

To summarize, individual differences in children's self-concepts of ability for academic activities were disrupted across the transition to junior high It seems likely that this disruption reflects two changes $(a)$ changes in the 
reference groups the children use as they try to infer their competence from avallable information, and $(b)$ changes in the information avallable to them regardıng their competence due to changes in their teachers' teaching and grading strategies In contrast, individual differences in their penceptions of their sports and social ability generally became more stable with age and did not show school transition effects We had expected this to be the case for sports self-concepts but had predicted a school transitional effect for selfconcept of social ability due to the disruption in the children's social networks caused by the school transition Instead, the school transition appears to have a general, negative impact on the children (as evidenced by the decline in the mean level of the children's self-concept of their social ability), but little unique impact on the stability of individual differences in the children's social ability self-concept

Changes in stabllity across time Effects of the Junior high transition and increasing age on percelved importance

Percelved importance of competence in math and English In general, for the sample as a whole, children's ratıngs of the importance of math competence were not disrupted by the transition to junior high school, but rather became more stable over time Individual differences in the children's ratings of the importance of math competence were more stable in junior high school than in elementary school and were not disrupted by the transition ( $1 \mathrm{e}$, the Waves 3 to 4 correlation was significantly higher than the Waves 1 to 2 correlation, and neither of these was significantly different from the Waves 2 to 3 correlation)

The same basic pattern of greater stability on the children's ratıngs of the importance of math competence in the seventh grade than in the sixth grade charactenzed the data for each sex separately Although the perceived importance of math competence was more stable for both girls and boys between Waves 2 and 3 than it had been in elementary school, this difference in stability was statistically significant only for the boys

Individual differences in the children's ratings of the importance of competence in English also became more stable over tıme and were significantly more stable in junior high school (Waves 3 to 4) than in elementary school (Waves 1 to 2) In addition, the transition to junior high school did not have a disruptive effect on individual differences in the children's rating of the importance of English competence ( $1 \mathrm{e}$, the correlation for Waves 2 to 3 was not significantly lower than the correlations for either Waves 1 to 2 or Waves 3 to 4 )

This pattern of increased stability in the individual differences in the perceived importance of English competence over time was true for both girls and boys ( $1 \mathrm{e}$, the Waves 3 to 4 correlations were significantly higher than 
the Waves 1 to 2 correlations) In addition, boys' ratıngs of English importance were also more stable in junior high school (Waves 3 to 4) than across the transition (Waves 2 to 3 ), this latter difference did not reach significance for the girls Thus, as was true for math, individual differences in children's ratings of the importance of English competence became more stable as the children got older and did not appear to be as disrupted by the transition to junior high school

Percelved importance of sports competence The same pattern of increasing stability in the individual differences characterized children's ratıngs of the importance of sports competence In this case individual differences in the ratings were significantly more stable at the transition (Waves 2 to 3 ) than in elementary school (Waves 1 to 2) and were significantly more stable in junior high school (Waves 3 to 4 ) than in elementary school or at the transition All three tests of the difference in the size of the across-time correlations tested were significant at $p<01$ for the whole sample and for boys The same pattern characterized the girls' ratings, but only the compansons of the Waves 1 to 2 correlation with the correlations for Waves 2 to 3 and Waves 3 to 4 were significant Though their ratungs became somewhat more stable in junior high than across the transition, this difference was not significant In sum, individual differences in the perceived importance of competence in sports became more stable from Waves 1 to 3 for all students and showed an additional significant increase in stability for boys durng seventh grade

Perceived importance of social competence Individual differences in children's ratings of the importance of social competence were significantly more stable in junior high school (Waves 3 to 4 ) than in elementary school (Waves 1 to 2) for the whole sample and for both boys and girls The pattern, however, was especially marked among boys Although there were no differences in stability between the two elementary school waves compared to the waves spanning the junior high transition for either girls or boys, there was a significant increase in the stability of boys' ratıngs of the importance of social competence during seventh grade as compared to the transition time penod (Waves 3 to 4 compared to Waves 2 to 3 ) This difference was not significant for the girls Thus, individual differences in the perceived importance of social competence became more stable over tume and were not disrupted by the junior high school transition

Generally, these results show that there is little disruption in the pattern of individual differences in children's ratings of the importance of their competence in different activity domains across the transition to junior high Instead, when differences were obtained they suggest that individual differences in the importance children attach to competence in each domain become more stable as children get older This finding is the strongest ev1- 
dence we found for the consolidation of one's identity during the early adolescent penod

\section{Stability of self-perceptions across different activity domains}

To examine how the beliefs about vanous activities differed in their stability, we compared the stability correlations to each pair of activities within a construct (self-concept of ability or importance) measured at the same two time points Due to limited space, we report only those patterns of compansons that yielded consistent evidence of the predicted domain differences

Self-concept of ablity Math versus English As predicted for the comparisons of the stability of individual differences in children's self-concept of math ability versus their self-concept of English ability, the beliefs about math were generally more stable than the beliefs about Enghsh For the whole sample, four of the six pairs were significantly different at the 01 level, in each case, self-concept of math ability was the more stable Only the pairs of correlations for Waves 1 to 4 and for Waves 3 to 4 did not differ For girls and boys separately, five of the six pairs were significant, in each case math self-concept was the more stable Only the pair of correlations for Waves 3 to 4 was not significantly different

Self-concept of ability Sports versus social ability Individual differences in children's self-concept of sports ability were by far the most stable of the ability perceptions For the whole sample, and for both boys and girls, either five or s1x self-concept of sports ability stability coefficients were significantly larger than the analogous coefficient for the children's self-concepts of their math, English, and social abilities

\section{Sex differences in the stability coefficients}

We compared the predicted stability correlations for boys and girls for each pair of the same variables measured at the same time points Hence for each activity and each construct we tested six pairs of correlations

Self-concept of ablity There was no consistent evidence of a sex difference in the stability of individual differences in self-concepts for the domains of math, English, and social abilities In contrast and as predicted, there were significant sex differences in the stability of individual differences in children's ability self-concepts for five of the six pairs of sports ability self-concept ratıngs In each case, individual differences in the boys' self-concepts of ability for sports were more stable than those of girls' ratings 
Percelved importance As was true for self-concepts, few significant sex differences in the stability coefficients emerged, and those that did were most likely to be in the sports domain No consistent evidence of a sex difference emerged for the math, English, or social domains In contrast and as predicted, four of the six pairs of correlations in the sports domain yielded significant sex differences at $p<01$ No sex differences were found for the Waves 1 to 2 or 1 to 3 compansons For each of the other four across-time stability coefficients, individual differences in the boys' importance ratings for sports competence were significantly more stable than those in the girls' ratıngs In summary, as for the self-concept of ability vanables, relatıvely few sex differences in importance ratıngs were obtained When differences were obtained, they favored boys, and, as predicted, most of these differences occurred in the sports domain

General discussion of stability findings In summary, most of our predictions regarding differences in stability coefficients across time and across the sexes were confirmed The stability of individual differences across these comparisons varied in a predictable manner Over time, the stability appears to increase as one would expect given a view of gradual identity consolidation over the early adolescent penod When this general developmental pattern is disrupted it occurs primarily for those domains in which the children's expenence with the critena they base their self-concepts on change most dramatically, $1 \mathrm{e}$, when they change teachers and schools Variations in stability across domains seem to reflect the degree to which the domains provide concrete performance evaluation criteria and the degree to which individual differences are considered to be stable by the culture at large Finally, there were relatively few sex differences in the stability of these constructs and those that emerged were primarily in the sports domain As predicted from gender-role theory, in this domain, the boys' beliefs were more stable than the gurls'

\section{Accuracy of Children's Self-Concept of Math Abulity}

To assess the accuracy of children's self-concepts, we correlated teachers' ratings of children's math ability with their self-concepts of math ability We used the sixth-grade teachers' ratings in the analyses at Waves 1 and 2, and the seventh-grade teachers' ratings in the analyses at Waves 3 and 4 The correlations are presented in Table 2 Contrary to our prediction and to previous findings reported by Harter (1982), there is no evidence of a general disruption in the accuracy of children's self-concepts of ability at the transition to junior high For the whole sample, and for both boys and girls sep- 
Table 2

Correlations of Children's Math Self-Concepts of Abllity With Teachers' Ratings of Their Mathematics Abllity at All Four Waves

\begin{tabular}{lrcccc}
\hline Group & $N$ & Wave 1 & Wave 2 & Wave 3 & Wave 4 \\
\hline Overall & 1031 & 54 & 56 & 54 & 63 \\
Girls & 555 & 50 & 50 & 50 & 60 \\
Boys & 476 & 59 & 67 & 60 & 68 \\
\hline
\end{tabular}

Note All correlations significant at the 001 level Sixth-grade teachers' ratings used data obtained at Waves 1 and 2, seventh-grade teachers' ratıngs used data from Waves 3 and 4

arately, significant differences occurred between the correlation of teacher ratıngs with students' self-concepts of ability at Wave 4 and the correlation of teacher ratings with students' self-concepts of ability at each of the other waves In each case the Wave 4 correlation was higher No other significant differences between pairs of correlations were observed This pattern supports the view that children's self-concepts of ability become more accurate with increasing age, but does not support the hypothesis that children's selfconcepts of academic ability would be least accurate immediately following the junior high school transition

Comparing the correlations for boys and girls yıelded significant differences at all four waves $(p<05)$ In each case, the correlations between the boys' self-concepts of math ability and the teacher ratings of their math ability were higher than those between girls' self-concepts of ability and the teacher ratings This result is consistent with our previous findings (Eccles, 1984 , Eccles, Adler, \& Meece, 1984) and suggests that boys' math self-concepts are not only higher than those for girls, they are also more closely tied to indicators of their school performance It is also the case, however, that individual differences in the boys' ability self-concepts are not more stable than individual differences in the girls' ability self-concepts So while the weightıng of the criteria may differ for boys and girls, the belief, once formed, is equally stable across the sexes

\section{GENERN DISCUSSION}

Since we have included much of our discussion in the Results section, we will limit our comments here to the issue most central to the theme of this special issue stability versus change in personality during the early adolescent period Given the general stereotype of early adolescence as a penod of storm and stress, there is remarkable stability and consistency in the variables discussed in this article at both the individual and group level At the 
individual level, the stability coefficients across waves are quite high, especially for the number of items comprising each indicator This is true both within the school year and across the junior high school transition Second, the indicators of the accuracy of the children's math self-concepts are also fairly stable across time, despite the fact that the criterion (their teacher's ratıng of their ability) comes from a different source in the two grade levels

At the group level, there are also several indications of stability First, even though we obtained significant wave effects on the means for the selfconcepts of ability, the domain importance, and the self-esteem vaniables, many of the differences are actually quite small Second, we found no significant Sex $\times$ Wave or Value Group $\times$ Wave interactions The distinctions between the groups at Wave 1 remain significant throughout the time penod studied here even though early adolescence is considered a time of changing values

Nonetheless, in our analyses there is also evidence of systematic, predictable change at both the individual and the group level We had predicted that change in the variables associated with school and academic subjects would be most marked between Waves 2 and 3 when the school transition takes place We found several incidences of support for this suggestion First, at the individual level, the two-wave stability coefficients that showed the most change across the school transition were the stability coefficients for selfconcept of math and English ability Second, at the group level, we found evidence of school transition effects for the means on math, English, and social self-concepts, general self-esteem, and the importance of English In addition, the pattern of most of these changes was consistent with our hypothesis regarding when the impact of the junior high school transition would be manifest in the students' ratings For math, it occurred, as one would expect, during seventh grade, given the probable incubation period for teacher effects In contrast, the change occurred immediately after the transition for self-esteem and social self-concept as one would expect if the transition had disrupted the children's social networks Finally, self-esteem showed the expected rebound effect across the seventh grade

The fact that we can make both within-school year and between-school year comparisons is one of the most powerful aspects of the design used in this study This design allows us to pinpoint the time period in which the change is occurring much more accurately than a 2-year study with a twowave design Looking across our various indicators, we see clear evidence of differential patterns of change on self-concepts of ability and self-esteem measures that make sense given what we know about the social environments of these children Those variables most vulnerable to the junior high school transition by and large showed either an immediate or a delayed transition effect Those variables most vulnerable to withın-year adjustment processes by and large showed within-year effects (e $g$, self-esteem) for both 
years The longitudinal effects on domain importance are less predictable, perhaps because values are not yet fully formed, as is indicated by the fact that these variables consistently have lower stability coefficients than the self-concepts of ability and self-esteem variables

\section{REFERENCES}

Berndt, T J (1987, April) Changes in friendship and school adjustment after the transition to junior high school Paper presented at the biennial meetung of the Society for Research in Child Development, Baltumore

Brush, L (1980) Encouraging girls in mathematics The problem and the solution Cambridge, MA Abt Books

Crockett, L , Losoff, M , \& Petersen, A (1984) Perceptions of the peer group and fnendship in early adolescence Journal of Early Adolescence, 4, 155-181

Damon, W, \& Hart, D (1986) Stability and change in children's self-understanding Social Cognition, 4, 102-118

Dusek, J B , \& Flaherty, J F (1981) The development of the self-concept during the adolescent years Monographs of the Society for Research in Child Development, 46, (4)

Eccles, J S (1984) Sex differences in achievement patterns In T Sonderegger (Ed), Nebraska symposium on mottvation, 32, 97-132

Eccles, J S (1987a) Adolescence Gateway to gender-role transcendence In D B Carter (Ed), Current conceptions of sex roles and sex typing (pp 225-242) New York Praeger

Eccles, J S (1987b) Gender roles and women's achievement-related decisions Psychology of Women Quarterly, 11, 135-172

Eccles, J S (1988) Psychological and behavioral underpinnings of performance Final report for Grant \#R01-HD17296 to National Institute of Chuld Health and Human Development, Washington, DC

Eccles, J S , Adler, T F, Futterman, R , Goff, S B , Kaczala, C M, Meece, J L, \& Midgley, C (1983) Expectancies, values, and academic behaviors In J T Spence (Ed), Achlevement and achievement mottvation (pp 75-146) San Francisco W H Freeman

Eccles (Parsons), J S , Adler, T F , \& Meece, J L (1984) Sex differences in achievement A test of altemate theones Journal of Personality and Social Psychology, 46, 26-43

Eccles, J S , \& Midgley, C (in press) Stage/environment fit Developmentally appropriate classrooms for early adolescents In R E Ames \& C Ames (Eds), Research on mottvation in education (Vol 3) New York Academic Press

Eccles (Parsons), J S , Midgley, C , \& Adler, T (1984) Grade-related changes in the school environment Effects on achievement motivation In J G Nicholls (Ed), The development of achievement mottvation (pp 283-331) Greenwich, CT JAI Press

Epstein, S (1973) The self-concept revisited or a theory of a theory American Psychologist, 28, 405-416

Erikson, E H (1968) Identity Youth and crists New York Norton 
Feldlaufer, H , Midgley, C , \& Eccles, J S (1988) Student, teacher, and observer perceptions of the classroom environment before and after the transition to jumior high school Journal of Early Adolescence, 8, 133-156

Feldlaufer, H , Midgley, C , \& Eccles, J S (in press) Student/teacher relations and attitudes toward mathematics before and after the transition to junior high school Child Development

Harter, S (1981) A new self-report scale of intrinsic versus extrinsic onentation in the classroom Motivational and informational components Developmental Psychology, 17, 300-312

Harter, S (1982) The Perceived Competence Scale for Children Child Development, $53,87-97$

Harter, S (1983) Developmental perspectives on the self-system In E M Hetherington (Ed ), Handbook of child psychology Social and personality development (4th ed , Vol 4, pp 275-385) New York Wiley

Harter, S (1985a) Competence as a dimension of self-evaluation Toward a comprehensive model of self-worth In R L Leahy (Ed), The development of the self (pp 55121) New York Academic Press

Harter, S (1985b) Processes in the formation, maintenance, and enhancement of the self-concept In J Suls \& A Greenwald (Eds), Psychological perspectives on the self (Vol 3, pp 137-181) Hillsdale, NJ Lawrence Erlbaum

Higgins, E T, \& Parsons, J E (1983) Social cognition and the social life of the child Stages as subcultures In E T Higgins, D W Ruble, \& W W Hartup (Eds ), Social cognitıon and social behavior Developmental issues (pp 15-62) New York Cambridge University Press

Hill, J P, \& Lynch, M E (1983) The intensification of gender-related role expectatrons during early adolescence In J Brooks-Gunn \& A C Petersen (Eds), Girls at puberty (pp 201-228) New York Plenum

James, W (1963) The principles of psychology New York Holt (Original work published 1890)

Kaczala, C M (1983) Sex role identtty and ts effect on achevement Attitudes and behaviors Unpublished doctoral dissertation, University of Michigan, Ann Arbor

Kagan, J , \& Moss, H (1962) Birth to maturty New York Wiley

Kıhlstrom, J F, \& Cantor, N (1984) Mental representations of the self In L Berkowitz (Ed), Advances in experimental social psychology (Vol 17, pp 2-47) New York Academic Press

Kırk, R E (1968) Experimental design Procedures for the behavtoral sciences Belmont, CA Brooks/Cole

Lerner, R M (1986) Concepts and theortes of human development New York Random House

Markus, H , \& Nunus, P (1986) Possible selves American Psychologist, 41, 954-969

McNemar, Q (1969) Psychological statistics (4th ed ) New York Wiley

Midgley, C , \& Feldlaufer, H (1987) Students' and teachers' decision-makıng fit before and after the transition to junior high school Journal of Early Adolescence, 7, 225241

Midgley, C , Feldlaufer, H , \& Eccles, J S (in press) The transition to junior high school Beliefs of pre- and post-transition teachers Journal of Youth and Adolescence 
Moore, D W (1983, April) Impact of school grade-organtzatzon patterns on seventh and eighth grade students in $\mathrm{K}-8$ and junior high school Paper presented at the annual meeting of the New England Research Association, Rockport, ME

Nottelman, E D (1987) Competence and self-esteem during the transition from childhood to adolescence Developmental Psychology, 23, 441-450

O'Malley, P M , \& Bachman, J G (1983) Self-esteem changes and stability between ages 13 and 23 Developmental Psychology, 19, 257-268

Parsons, J E (1980) Self-perceptions, task perceptions and academic choice Origins and changes Final technical report to the National Institute of Education, Ann Arbor, MI (University Microfilms No 86-12,609)

Parsons, J S , \& Bryan, J (1978) Adolescence Gatewav to androgyny Occasional Paper series, Women's Studies, University of Michigan, Ann Arbor

Power, C (1981) Changes in students' attitudes toward science in the transition between Australian elementary and secondary schools Journal of Research in Sctence Teaching, 18, 33-39

Rosenberg, M (1979) Conceiving the self New York Bastc Books

Shalvelson, R J , \& Bolus, R (1982) Self-concept The interplay of theory and methods Journal of Educational Psychology, 74, 3-17

Shavelson, R J, Hubner, J J , \& Stanton, G C (1976) Self-concept Validation of construct interpretations Review of Educational Research, 46, 407-441

Simmons, R G, \& Blyth, D A (1987) Moving into adolescence The impact of pubertal change and school context Hawthorn, NY Aldine de Gruyler

Simmons, R G , Rosenberg, F , \& Rosenberg, M (1973) Disturbance in the self-image at adolescence American Sociological Review, 38, 553-568

Stein, A H , \& Smithells, J (1969) Age and sex differences in children's sex role standards about achievement Development Psychology, 1, 252-259

Thornberg, H D , \& Jones, R M (1982) Social charactenstics of early adolescents Age versus grade Journal of Early Adolescence, 2, 229-239

-Walker, L S, \& Greene, J W (1986) The social context of adolescent self-esteem Journal of Youth and Adolescence, 15, 315-322

Manuscript recetved June 4, 1988 revised February 13, 1989 
This document is a scanned copy of a printed document. No warranty is given about the accuracy of the copy. Users should refer to the original published version of the material. 